\title{
Integrated study of 100 patients with Xp21 linked muscular dystrophy using clinical, genetic, immunochemical, and histopathological data. Part 3. Differential diagnosis and prognosis
}

Louise V B Nicholson, Margaret A Johnson, Kate M D Bushby, David Gardner-Medwin, Ann Curtis, Ieke B Ginjaar, Johan T den Dunnen, John L Welch, Tim J Butler, Egbert Bakker, Gert-Jan B van Ommen, John B Harris

Muscular Dystrophy Group Research Laboratories, Regional

Neurosciences Centre, Newcastle General

Hospital, Newcastle upon Tyne NE4 6BE, UK.

L V B Nicholson

M A Johnson

K M D Bushby

D Gardner-Medwin

J B Harris

Department of Human Genetics, University of

Newcastle upon Tyne

NE2 4AA, UK.

A Curtis

Department of Human Genetics,

Sylvius Laboratory,

2333 AL Leiden, The

Netherlands.

H B Ginjaar

$\mathrm{J} T$ den Dunnen

E Bakker

G-J B van Ommen

Department of Neuropsychology,

Newcastle General

Hospital NE4 6BE,

UK.

$\mathrm{J}$ L Welch

Department of Medical Statistics, University of Newcastle upon Tyne NE2 4HH, UK.

Correspondence to Dr Nicholson,

Neurochemistry

Department, Regional

Neurosciences Centre,

Newcastle General Hospital

Newcastle

Received 22 February 1993 Revised version accepted 22 April 1993.

\section{Abstract}

This report is the third part of a trilogy from a multidisciplinary study which was undertaken to investigate gene and protein expression in a large cohort of patients with well defined and diverse clinical phenotypes. The aim of part 3 was to review which of the analytical techniques that we had used would be the most useful for differential diagnosis, and which would provide the most accurate indication of disease severity. Careful clinical appraisal is very important and every DMD patient was correctly diagnosed on this basis. In contrast, half of the sporadic BMD patients and all of the sporadic female patients had received different tentative diagnoses based on clinical assessments alone. Sequential observations of quantitative parameters (such as the time taken to run a fixed distance) were found to be useful clinical indicators for prognosis. Intellectual problems might modify the impression of physical ability in patients presenting at a young age. Histopathological assessment was accurate for DMD but differentiation between BMD and other disorders was more difficult, as was the identification of manifesting carriers. Our data on a small number of women with symptoms of muscle disease indicate that abnormal patterns of dystrophin labelling on sections may be an effective way of differentiating between female patients with a form of limb girdle dystrophy and those carrying a defective Xp21 gene. Dystrophin gene analysis detects deletions/duplications in 50 to $90 \%$ of male patients and is the most effective non-invasive technique for diagnosis. Quantitative Western blotting, however, would differentiate between all Xp21 and non-Xp21 male patients. In this study we found a clear relationship between increased dystrophin abundance (determined by densitometric analysis of blots) and clinical condition, with a correlation between dystrophin abundance and the age at loss of independent mobility among boys with DMD and intermediate $D / B M D$. This indicates that blotting is the most sensitive and accurate technique for diagnosis and prognosis.

( 7 Med Genet 1993;30:745-51)
Since the gene which is defective in patients with Duchenne and Becker muscular dystrophy (DMD/BMD) was cloned, ${ }^{1}$ there has been a revolution in the techniques that can be applied to the investigation of patients with muscular dystrophy. For more than 30 years there has been a unit at Newcastle General Hospital which has been dedicated to research into diseases of muscle, so we have been able to compare the relative merits of various diagnostic techniques. In this study we examined a cohort of 100 patients with DMD and BMD and considered their clinical expression of disease severity in relation to the traditional laboratory investigations of histopathology and enzymology and to the more recent molecular techniques for dystrophin gene and protein expression. Since most of the patients had been observed for many years (some for all of their lives), this study provided us with a unique opportunity to review which of the data collected provided the most accurate reflection of their clinical condition.

Thus, in part 3 of this report we discuss which techniques were most useful for differentiating patients with DMD and BMD from those with other neuromuscular disorders, and for predicting what degree of disease severity might be expected. Since patients with DMD may require a wheelchair before they are 7 years old and patients with BMD may never need one, an accurate prognosis would help the families of affected patients to adjust their lives and homes to the future needs of a young patient.

\section{Materials and methods}

The patient groups are defined in part 1 , together with details of their clinical assessment. Techniques for genetic and protein analyses are described in parts 1 and 2. A figure illustrating Western blot lanes is shown in part 1. The clinical data and results of gene and protein expression are summarised in the Appendix in part 1.

\section{Results}

CLINICAL ASSESSMENT

Observation of the patients provides the basis for differential clinical diagnosis and this opinion may then be substantiated or contradicted 
by subsequent laboratory investigations. In this study there were no examples of initial clinicopathological misdiagnosis among patients now known to have DMD. In contrast, $11 / 35(31 \%)$ of the BMD patients (half of the isolated cases) and all (6/6) of the sporadic female patients had clinical records which included different tentative diagnoses. The alternative disorders included forms of adult limb-girdle dystrophy or spinal muscular atrophy (10 cases), autosomal recessive muscular dystrophy with onset in childhood (three cases), facioscapulohumeral muscular dystrophy (one case), and forms of metabolic myopathy characterised by cramps without muscle weakness (three cases). As for prognosis, in this cohort two patients with early presentation were initially diagnosed as DMD and are now thought to have BMD on the basis of relatively mild progression. Both patients were found to have the in frame deletion of exons 45 to 49 and to have high levels of dystrophin. There were no examples of the reverse situation, that is, DMD patients initially thought to be cases of BMD.

\section{HISTOPATHOLOGY AND CK ANALYSIS}

Classical histopathological techniques have been generally reliable in diagnosing DMD but the histological similarities between BMD and various limb-girdle syndromes has given rise to problems when there was no informative family history. Three of the BMD patients originally diagnosed as having other diseases had CK levels, on initial presentation, which were abnormally low for BMD, that is, only about 1.5 to 3 times normal (240 to $450 \mathrm{IU} / 1$ ). An abnormally high CK level (>35000 U/1) was found in one patient who first attended the clinic at 10 years and whose subsequent clinical course proved to be that of a 'typical' BMD patient. Some patients now known to have BMD were originally thought to have the Kugelberg-Welander form of spinal muscular atrophy on the basis of a bimodal fibre size distribution, which is usually indicative of a denervating process.

\section{GENETIC ANALYSIS}

Gene defects, which would differentiate between a diagnosis of Xp21 or non-Xp21 muscular dystrophy, were detected in $75 / 92$ $(81 \%)$ of the male patients, but only $1 / 7(14 \%)$ of the female patients. Patients with deletions which maintain the reading frame for mRNA translation were generally, but not exclusively, quite mildly affected. Three DMD patients had in frame deletions. All BMD patients in group 5 had in frame deletions which removed several exons within the rod domain and no deletion in this group started before exon 45 . In frame deletions in the amino domain were found only in group 3 intermediate D/BMD patients or in DMD patients in group 2. All patients with frameshifting deletions had relatively severe DMD or intermediate $\mathrm{D} / \mathrm{BMD}$ phenotypes.

\section{PROTEIN ANALYSIS}

Abnormalities of dystrophin protein expression were observed in all the patients with no detectable gene mutations. Thus, these 23 patients from a total of $98(23.5 \%)$ represented a group who may have been misdiagnosed on the basis of genetic data alone. Dystrophin immunocytochemistry was found to be particularly useful in the differential diagnosis of the female patients. Dystrophin negative fibres were the most significant feature observed, but these can also occur in damaged or necrotic fibres in biopsies from patients with non-Xp21 linked muscle disease (for example, fig 3 in Nicholson et $\left.a l^{2}\right) .^{2}$ In order to distinguish between true abnormalities of dystrophin expression and loss of dystrophin labelling owing to membrane damage, labelling for $\beta$ spectrin was used to confirm the integrity of the muscle membrane in dystrophin negative fibres (fig 1A,B).

Among male patients, the relationship between dystrophin labelling on sections and blots was simple in that both increased in parallel. In this study only two BMD patients had labelling which was indistinguishable from non-Xp21 on sections labelled with one or more antibodies, but the differentiation was not clear cut in a further five patients with an overall decrease in labelling intensity without really significant variation between and within fibres. In these cases where a subjective opinion was uncertain, densitometric analysis of blots was able to show a reduction in dystrophin abundance by more quantitative methods. Among the female patients the correlation between dystrophin labelling on tissue

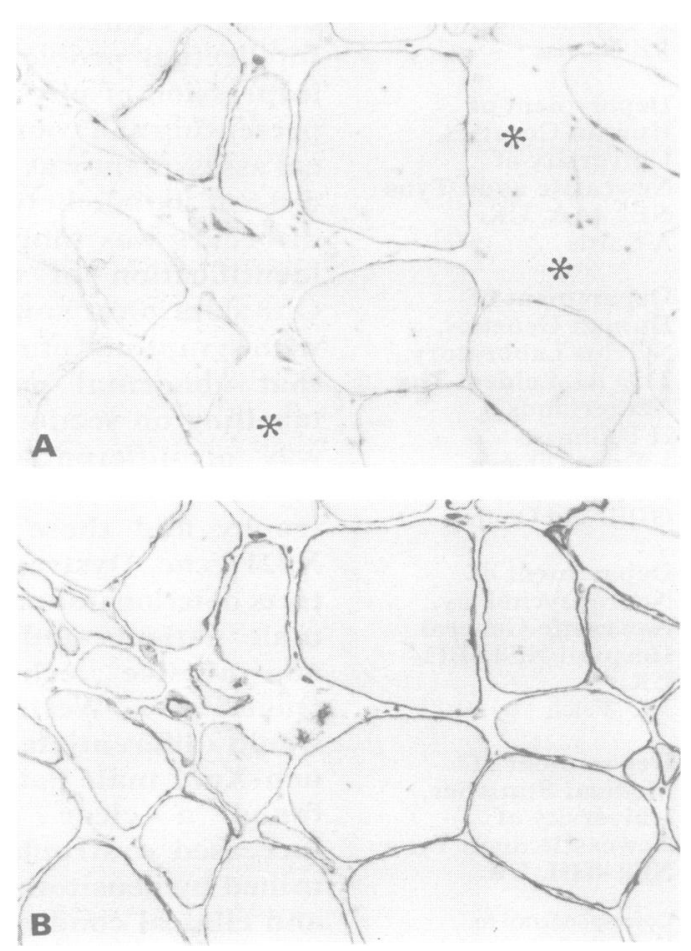

Figure 1 Serial sections from a manifesting carrier (S98) labelled with the C-terminal MAb Dy8/6C5 $(A)$ and the $\beta$-spectrin MAb RBC2/3D5. Examples of fibres which are dystrophin deficient are marked with asterisks. These dystrophin negative fibres are clearly spectrin positive, indicating that the lack of dystrophin labelling is not the result of loss of membrane integrity. (Indirect peroxidase.) 
sections and on blots was not as strong as in the male groups. For example, two female patients ( $S 98$ and S99 in the appendix in part 1) both had the same proportions of fibres labelled $(60 \%$ normal, $20 \%$ decreased, $20 \%$ negative) but the abundance of dystrophin was estimated to be 32 to $45 \%$ of normal for patient S98 and 70 to $80 \%$ of normal for patient S 99 . This was mainly because of the difficulty of discriminating between fibres with truly 'normal' immunolabelling and those with slightly decreased labelling.

In this study we found that the mean values for dystrophin abundance increased gradually across the clinical groups from severe DMD in group 1 to typical BMD in group 5 (see part 1 of this investigation). Almost $60 \%$ of DMD patients from groups 1 and 2 had low levels of dystrophin synthesised from mRNA in which the reading frame must have been restored. Since the presence of in frame dystrophin molecules is associated with milder clinical phenotypes, it was possible that this might have some prognostic significance. We therefore used results obtained with the rod domain antibody, Dy4/6D3, to examine more closely the correlation between clinical severity and estimates of dystrophin abundance. We used the age at which boys lose the ability to walk independently (requiring full length callipers or a wheelchair) as a measure of muscle strength. Excluding an atypical DMD patient (S39, who had a BMD-like dystrophin profile), and three patients with deletions which removed the Dy $4 / 6 \mathrm{D} 3$ antibody binding site, a total of 33 DMD patients and seven intermediate $\mathrm{D} / \mathrm{BMD}$ patients had lost independently mobility at the end of the study when results were collated. Quantitative estimates of dystrophin abundance were obtained from densitometric analysis of dystrophin bands on blots. Among the set of 40 patients a significant positive relationship $(\mathrm{r}=0.66, \mathrm{p}<0.00001)$ was found between the age when boys could no longer walk independently and the abundance of dystrophin determined with the rod $\mathrm{MAb}$ Dy4/6D3 (fig 2). It was also noted that, as dystrophin abundance on blots increased, so did the incidence of a particular pattern of labelling on tissue sections. This consisted of a high proportion of fibres with very weak label-

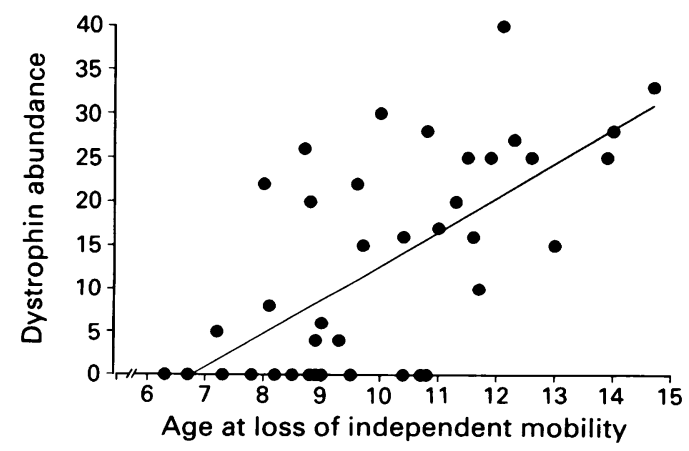

Figure 2 Age at loss of independent mobility and dystrophin abundance estimated from blots labelled with dystrophin abundance estimated from blots labelled
the rod $M A b$ Dy $4 / 6 D 3$. In general, estimates of dystrophin abundance increased with the length of time that boys maintained independent mobility. The correlation coefficient for the data on these 40 patients is 0.66 which is highly significant $(p<0.00001)$. ling in addition to a small percentage of fibres with clear dystrophin positive labelling. This was observed rarely in group 1 severe DMD patients, more frequently in group 2 milder DMD patients, and was the most typical labelling pattern seen in the group 3 intermediate $\mathrm{D} / \mathrm{BMD}$ biopsies.

\section{Discussion}

CLINICAL ASSESSMENT

The variation in clinical severity of patients spanning a wide age range meant that this study presented an ideal opportunity to compare the techniques used for diagnosis and prognosis before and after the 'dystrophin era'. For diagnosis the requirement for careful clinical assessment has not changed, and sequential observations of quantitative clinical parameters such as the time taken to run a certain distance are still of great importance in predicting the ultimate prognosis. ${ }^{3}$ Such measurements are needed over three or four years, however, before the slope of time/age is of prognostic value for any individual patient.

Clinical appraisal may be complicated by reduced intellectual ability in some DMD patients. Furthermore, scores for IQ in the small number of intermediate $D / B M D$ and BMD patients we tested (see part 2) showed that these patients were mostly of below average intelligence, although none was actually retarded. Sporadic cases of BMD, who came to the clinic at an unusually early age, presented with problems (for example, late walking) which, in retrospect, seemed to be related more to intellectual or behavioural problems than to problems of muscle function. One BMD patient (S75) was originally diagnosed as having DMD because of this. Similarly, the young patient S3 had an initial clinical diagnosis of DMD and was then found to have a high abundance of dystrophin with both rod and C-terminal MAbs. Interestingly, both these patients are missing exons 45 to 49 . Other BMD patients with this particular deletion seem to have behavioural or antisocial problems. ${ }^{4}$ One large family in Brazil had members with BMD and clinical schizophrenia whereas non-BMD family members did not have this problem. The deletion of this family was also of exons 45 to $49 .^{5}$

\section{CK LEVELS AND HISTOPATHOLOGY}

Two laboratory investigations which have supplemented the clinical appraisal for many years are the measurement of serum levels of muscle enzymes like creatine kinase (CK), and the assessment of histopathology in muscle biopsies. Although CK levels are excellent for differentiating myopathic from neurogenic disorders, the rise in level is primarily age related and single measurements are of limited value for prognosis, although Zatz et $a l^{6}$ found that the rate of decline in CK activity per year was informative. Differentiation between $\mathrm{Xp} 21$ and non-Xp21 on the basis of CK can be difficult, but a grossly raised level (for example over $20000 \mathrm{IU} / 1)$ usually indicates DMD.? 
Measurement of CK levels is still considered to be a very important part of carrier detection and the use of age related normal values improves its usefulness. ${ }^{8}$

In very general terms, histopathological assessment of muscle biopsies can potentially differentiate myopathic from neurogenic disorders and dystrophic from inflammatory processes. Furthermore, although the assessment may be regarded as a rather subjective process, in the case of DMD the pattern of histological abnormalities is sufficiently characteristic to pose few problems for the experienced observer. By contrast, biopsies from patients in the early stages of BMD and from patients with severe autosomal recessive muscular dystrophy of childhood may both show a particular 'clustered' distribution of necrotic and/or regenerating fibres, ${ }^{9}$ and in the absence of informative family histories, this can be a source of diagnostic uncertainty. Chronic muscular dystrophies, including BMD and forms of limb-girdle dystrophy, tend to show similar histopathological features and some BMD biopsies may show features which are reminiscent of neurogenic disorders (see also Bradley et $a l^{10}$ and Kaido et $a l^{11}$ ). Thus the positive identification of BMD patients by means of dystrophin analysis represents a significant advance in diagnostic practice, and recent data on the incidence and prevalence of BMD emphasise how this condition has been underdiagnosed in the past. ${ }^{12}$ The differentiation of women who are manifesting carriers of DMD/ BMD from those who have autosomally inherited limb-girdle dystrophies on histological grounds alone was also impossible before the introduction of dystrophin analysis.

Quantitative analysis of histopathological features such as the percentage of fibrous connective tissue and the degree of fibre size variation showed clear trends across the clinical groups from DMD to BMD (see part 1). This was in spite of the fact that these features are, to some extent, determined by the age at which biopsies are taken (also see Kaido et $\left.a l^{11}\right)$. Analysis of variance showed that the trends across the clinical groups were significant but the lack of statistical difference between any two adjacent groups indicated that there was a wide overlap of values. It follows, therefore, that quantitative analysis of this sort has little prognostic use in individual patients.

\section{GENETIC ANALYSIS}

In this investigation we found an unusually high percentage of mutations $(75 / 98$ or $76 \%$ overall) among our patients (see part 1). Previous large studies indicate that 55 to $65 \%$ are more typical values, ${ }^{13-15}$ although a much higher percentage $(86 \%)$ has been reported among patients where the initial clinical diagnosis has been confirmed by dystrophin protein abnormalities. ${ }^{1617}$ Southern blotting is expensive and time consuming and so routine genetic analysis is now more likely to involve polymerase chain reaction (PCR) based tech- niques. In a recent comparative study of 745 unrelated male patients, mutations were detected in $427(57 \%)$ by Southern blotting and in $346(46 \%)$ by multiplex PCR analysis. ${ }^{15}$ This indicates that more than half of the patients with Duchenne or Becker muscular dystrophy might not be distinguished from those with non-Xp21 linked disorders in a routine laboratory using PCR analysis alone. In this study, the mutations in three of 35 DMD patients with deletions (missing exons 20 to 29,22 to 41 , and 64 to 66 ) would have been missed, even using an optimised multiplex PCR system like that of Abbs et al. ${ }^{18}$ Furthermore, since the multiplex primers do not cover every exon and junctional fragments are not detected by PCR methods, the effect of mutations on the open reading frame would also be very difficult to assess.

In this study we found that prognosis based on the open reading frame was generally quite effective at differentiating DMD (with frameshifting deletions) from BMD (with in frame deletions, primarily in the distal 'hotspot'). We found a very close correlation between a mild clinical phenotype and deletion of exons 45 to 47,45 to 48 , and 45 to 49 but there are reports of some 'DMD' patients with these deletions. ${ }^{1314}{ }^{19-22}$ In these papers, however, the young age of some of the patients or the lack of dystrophin analysis makes comparisons very difficult. Furthermore, errors may have been made in the initial reports so that some of the DMD patients first recorded as missing certain HindIII fragments (which are now known to correspond to in frame deletions, for example, exons 45 to 48 ) have since been reassessed (S Abbs, personal communication concerning the data in Hodgson et al ${ }^{19}$ ). In frame deletions in the amino domain were associated with a more severe clinical phenotype than was found with distal in frame deletions, an observation in agreement with Beggs et al. ${ }^{16}$ Intermediate $\mathrm{D} / \mathrm{BMD}$ patients had mutations which were both in frame and out of frame, and three DMD patients had in frame deletions. Prognosis for these DMD patients, based on genetic analysis alone, would therefore be inaccurate.

\section{PROTEIN ANALYSIS}

While analysis of the dystrophin gene is noninvasive, analysis of dystrophin protein has the obvious drawback of requiring a muscle biopsy, and although needle biopsies are performed almost exclusively at many centres, open biopsies are generally performed in Newcastle. Larger biopsy samples are less likely to have artefactual damage to muscle membranes and will provide sufficient material for efficient extraction of proteins for Western blotting. Exactly how representative the sample will be is a moot point. The finding of patients with dissimilar patterns of dystrophin labelling in two different muscles emphasises this problem. ${ }^{2324}$ The requirement for dystrophin analysis to be performed with antibodies from different regions of the molecule has also been emphasised. ${ }^{25} \mathrm{C}$-terminal antibodies will not 
detect any truncated dystrophin molecules ${ }^{27}$ and may lose their binding sites owing to the susceptibility of this region to degradation. ${ }^{2829}$ Antibodies in the amino or rod domains may lose their binding sites through the action of gene deletions. ${ }^{16273031}$

Immunocytochemistry of dystrophin using multiple antibodies, combined with the use of $\beta$-spectrin labelling as an essential indicator of membrane integrity, is extremely cost effective when compared with Western blotting (which is rather labour intensive and expensive). All cases of DMD and more than $80 \%$ of BMD cases could be detected from labelling of tissue sections. Most, if not all, manifesting carriers show dystrophin protein abnormalities ${ }^{32-36}$ and therefore immunocytochemical analysis is an effective way of differentiating between a sporadic female with a form of limb-girdle dystrophy and a manifesting carrier of a defective $\mathrm{Xp} 21$ gene. In addition, an unknown proportion of non-manifesting carriers of $\mathrm{DMD}^{243234}{ }^{37}$ or $\mathrm{BMD}^{38} 39$ may show abnormal dystrophin labelling. Data from larger numbers of non-manifesting obligate carriers would be required to assess the reliability of dystrophin analysis in carrier detection.

Although immunocytochemistry is cost effective, there are very distinct advantages to the additional use of blots, in which all the immunoreactive protein present is detected. For example, if a sample has been thawed, or subjected to degradation (for example, some fetal material), labelling on sections may appear patchy or absent but the detection on blots of clearly labelled breakdown products with abnormally low molecular mass will prevent misdiagnosis. We are not aware of any examples in published reports where dystrophin analysis by Western blotting has failed to detect a patient with confirmed DMD or BMD, so it is tentatively assumed that all male patients could be detected by this form of protein analysis.

Blots may be used to estimate dystrophin abundance and this may be a very sensitive prognostic indicator. In this study we have shown that there is a gradual increase in dystrophin abundance (DMD $<\mathrm{D} / \mathrm{BMD}<\mathrm{BMD})$ with improving clinical condition, and prognoses based on dystrophin abundance are currently being monitored very closely. In this study we have found a clear correlation between dystrophin abundance and the age at which DMD and intermediate D/BMD boys lost the ability to walk independently. As more of the boys become unable to walk we will be able to confirm or revise our original observation. It should be emphasised that these data are not being used in any formal counselling of families with DMD. The correlation, while statistically significant, was not absolute and a few patients with relatively high dystrophin levels lost mobility earlier than the population average of 9 years. Conversely, three boys with undetectable dystrophin on blots (but a few fibres labelled on sections) remained ambulatory until they were more than 10 years old. A possible explanation for this apparent discrepancy is that the biopsy sample taken for analysis was not representative of the musculature as a whole. We, and others, have noted that dystrophin labelling patterns may vary from fasicle to fasicle, that different blocks of tissue from the same biopsy may show different labelling patterns, and that when repeat biopsies are performed considerable variation may occur. ${ }^{232440}$ Previous studies have found no relationship between the incidence of dystrophin positive fibres and clinical course, ${ }^{2541}$ but a blotting system may be more sensitive for quantitating all the potentially functional dystrophin present. Low levels of immunoreactive dystrophin protein which are spread out on a tissue section (= weak labelling on many fibres) are concentrated into a single band on a blot, which makes visualisation much easier. Dystrophin analysis in female patients was much more valuable than in male patients. No clear relationship was found between labelling on blots and sections, as has been noted previously, ${ }^{4243}$ or between clinical severity and either form of protein analysis.

Protein analysis has produced some cautionary tales, however, and a small number of cases has now been reported where such analysis would provide a misleading prognosis. A few patients with the clinical phenotype of DMD have now been identified who have in frame deletions and abundant, correctly localised dystrophin which was detectable with C-terminal antibodies. We recorded one such case in this study (reported in detail previously ${ }^{44}$ ), who was deleted for exons 3 to 25 . Two similar patients with this deletion have also been described, ${ }^{45}$ together with patients missing exons 3 to $31,{ }^{45} 3$ to 44 , and 10 to $47 / 48 .^{46}$ These are all large deletions, and the fact that they start in the amino domain may well be significant since very few patients with mild clinical phenotypes have deletions which involve proximal exons.

From the viewpoint of potential problems with differential diagnosis, some false positive examples of abnormal dystrophin protein expression have been reported in association with certain non-Xp21 linked muscle diseases. These examples include $34 / 36$ cases of Fukuyama muscular dystrophy, ${ }^{47}$ one case of autosomal recessive congenital muscular dystrophy, ${ }^{23}$ and some patients with inflammatory myopathies. ${ }^{2348}$ The abnormalities in dystrophin expression in the cases of Fukuyama muscular dystrophy may be related to a more generalised plasma membrane defect or to a specific interaction between dystrophin and the FCMD gene product. ${ }^{479}$ In other conditions the abnormalities are likely to be caused by secondary myopathic changes, and it seems probable that clinical and histopathological assessments would preclude patients with myositis from serious consideration as potential DMD or BMD patients.

\section{CONCLUSION}

Physical examination by an experienced clinician is probably still the most important technique for diagnosis. There are exceptions, however, and the accurate diagnosis of a spora- 
dic case of BMD is complicated by the variation in presenting symptoms..$^{50-53}$ Clinical appraisal can provide a good indication of prognosis, but this may take several years if the patient is very young. In general we would agree with the algorithm for the molecular diagnosis of DMD and BMD which Darras ${ }^{54}$ presented in 1990. The diagnosis of a new patient from a family in which DMD or BMD has previously been confirmed by gene or protein analysis presents few real problems, beyond consideration of intrafamilial variation in disease expression. For a young patient with no family history, however, a number of possible laboratory investigations exist. Genetic analysis can be performed on cells from a blood sample and is therefore much less traumatic than techniques which require a muscle biopsy. Analysis of deletions by PCR is the most cost effective method for diagnosis in a routine laboratory which receives samples from a large number of patients. Although the method has the potential to detect all the deletions found by Southern blotting, in practice primers for about 18 exons only are in regular use. Since deletions/duplications of exons are only present in about 65 to $85 \%$ of cases anyway, it is much more difficult to exclude a diagnosis of $\mathrm{Xp} 21$ linked muscular dystrophy by genetic methods. If a muscle biopsy is taken, the most accurate method for diagnosis is quantitative Western blotting analysis of a muscle sample, but this is also the most expensive and time consuming. Immunocytochemistry is considerably cheaper and faster and is as effective as blotting for the diagnosis of DMD patients. Immunocytochemistry may also be the most effective way of differentiating between a woman with a form of limb-girdle dystrophy and a nondeleted manifesting carrier of DMD or BMD.

Thus, if the diagnostic choice is between $D M D$ and a form of autosomal recessive $M D$ we would recommend genetic analysis by PCR and muscle immunocytochemistry. If the choice is between BMD and a form of autosomal MD, we would recommend PCR and immunoblotting. Prognosis within the clinical spectrum of DMD and BMD may best be achieved by immunoblotting or Southern blotting for confirmation of deletion boundaries and analysis of reading frame effects. Some techniques produce far fewer 'exceptions to the rule' than others, as discussed above, but it would be wise to exercise a degree of caution in the interpretation of all results. It is also likely that any protocol will need to be modified by local considerations such as objections to having a biopsy performed, the availability of Western blotting facilities, the time taken to receive results from the different types of analysis, and unfortunately, in these days of financial restraint, the expense which may be incurred by requesting an extensive set of analyses.

This study relied for a large part on the technical expertise of Keith Davison, Martin Barron, Liz O'Donnell, Gavin Falkous, Daisy Haggerty, and Marleen van Paassen for which we are extremely grateful. We also wish to thank Dr D Mantle for the serum creatine kinease analysis. The financial support of the University of Newcastle upon Tyne Research Committee, the Muscular Dystrophy Group of Great Britain, the Wellcome Trust, the Medical Research Council, the Association Française contre les Myopathies (AFM), the Princess Beatrix Fund, the Dutch Prevention Fund, and The Netherlands Foundation of Medical Research (MEDIGON) is gratefully acknowledged.

1 Koenig M, Hoffman EP, Bertelson CJ, et al. Complete cloning of the Duchenne muscular dystrophy (DMD) CDNA and preliminary genomic organization of the DMD gene in normal and affected individuals. Cell 1987;50:509-17.

2 Nicholson LVB, Johnson MA, Gardner-Medwin D, Bhattacharya S, Harris JB. Heterogeneity of dystrophin expression in patients with Duchenne and Becker muscular dystrophy. Acta Neuropathol 1990;80:239-50.

3 Bushby KMD. Genetic and clinical correlations of Xp21 muscular dystrophy. $\mathcal{F}$ Inherited Metab Dis 1992;15:55164.

4 Bushby KMD, Gardner-Medwin D, Nicholson LVB, et al. The clinical, genetic and dystrophin characteristics of
Becker muscular dystrophy. II. Correlation of phenotype Becker muscular dystrophy. II. Correlation of phenotype with genetic an

5 Zatz M, Vallada H, Melo MS, et al. Cosegregation of schizophrenia with Becker muscular dystrophy: susceptibility locus for schizophrenia at Xp21 or an effect of the dystrophin gene in the brain? 7 Med Genet 1993;30:131-4

6 Zatz M, Rapaport D, Vainzof M, et al. Serum creatinekinase (CK) and pyruvate kinase (PK) activities in Duchenne (DMD) as compared with Becker (BMD) muscular dystrophy. F Neurol Sci 1991;102:190-6.

7 Emery AEH. Duchenne muscular dystrophy. Revised edition. Oxford: Oxford University Press, 1988.

8 Passos-Bueno MR, Otto PA, Zatz M. Estimates of conditional heterozygosity risks for young females in Duchenne muscular dystrophy. Hum Hered 1989;39:202 11.

9 Dubowitz V. The muscular dystrophies. In: Muscle biopsy a practical approach. London: Baillière Tindall, 1985:289-404

10 Bradley WG, Jones MZ, Mussini JM, Fawcett PRW. Becker-type muscular dystrophy. Muscle Nerve 1978;1:111-32.

11 Kaido M, Arahata $\mathrm{K}$, Hoffman EP, Nonaka I, Sugita $H$ Muscle histology in Becker muscular dystrophy. Muscle Nerve 1991;14:1067-73.

12 Bushby KMD, Thambyayah M, Gardner-Medwin D. Prevalence and incidence of Becker muscular dystrophy. Lancet 1991;337:1022-4.

13 Koenig M, Beggs AH, Moyer M, et al. The molecular basis for Duchenne versus Becker muscular dystrophy: correlation of severity with type of deletion. Am $\mathcal{f}$ Hum Gene 1989;45:498-506.

14 den Dunnen JT, Grootscholten PM, Bakker E, et al. Topography of the Duchenne muscular dystroph (DMD) gene: FIGE and CDNA analysis of 194 cases reveals 115 deletions and 13 duplications. Am $\mathcal{f}$ Hum Genet 1989;45:835-47.

15 Multicenter Study Group. Diagnosis of Duchenne and Becker muscular dystrophies by polymerase chain reaction. f Am Med Assoc 1992;267:2609-15.

16 Beggs AH, Hoffman EP, Snyder JR, et al. Exploring the molecular basis for variability among patients with Becker molecular basis for variability among patients with Becker Am f Hum Genet 1991;49:54-67.

17 Specht LA, Beggs AH, Korf B, Kunkel LM, Shapiro F Prediction of dystrophin phenotype by DNA analysis in Duchenne/Becker muscular dystrophy. Pediatr Neurol 1992;8:432-6.

18 Abbs S, Yau SC, Clark S, Mathew CG, Bobrow M. A convenient multiplex PCR system for the detection of dystrophin gene deletions: a comparative analysis with cDNA hybridisation shows mistypings by both methods. f Med Genet 1991;28:304-11.

19 Hodgson S, Hart K, Abbs S, et al. Correlation of clinical and deletion data in Duchenne and Becker muscular dystrophy. F Med Genet 1989;26:682-93.

20 Lucotte G, David F, Levy C. Molecular deletion patterns in Duchenne muscular dystrophy patients. Ann Genet Duchenne muscular dyst

21 Upadhyaya M, Smith RA, Thomas NST, Norman AM, Upadhyaya M, Smith RA, Thomas NST, Norman AM, Harper PS. Intragenic deletions in 164 boys with trophin cDNA. Clin Genet 1990;37:456-62.

22 Rapaport D, Passos-Bueno MR, Brandao L, et al. Apparent association of mental retardation and specific patterns of deletions screened with probes Cf56a and Cf23a in Duchenne muscular dystrophy. Am $\mathcal{f}$ Med Genet 1991;39:437-41.

23 Voit T, Stuettgen P, Cremer M, Goebel HH. Dystrophin as a diagnostic marker in Duchenne and Becker muscular 
dystrophy. Correlation of immunofluorescence and Western blot. Neuropediatrics 1991;22:152-62.

24 Muntoni F, Mateddu A, Marrosu MG, et al. Variable dystrophin expression in different muscles of a Duchenne muscular dystrophy carrier. Clin Genet 1992;42:35-8.

25 Vainzof M, Zubrzycka-Gaarn EE, Rapaport D, et al. Immunofluorescence dystrophin study in Duchenne dysImm through the concomitant use of tuch antib dy trophy through the concomitant use of two antibodies directed against the carboxy-terminal and the amino-
terminal region of the protein. $\mathcal{F}$ Neurol Sci 1991;101:1417 .

26 Arahata $\mathrm{K}$, Beggs $\mathrm{AH}$, Honda $\mathrm{H}$, et al. Preservation of the C-terminus of dystrophin molecule in the skeletal muscle from Becker muscular dystrophy. $f$ Neurol Sci 1991;101:148-56.

27 Bulman DE, Murphy EG, Zubrzycka-Gaarn EE, Worton RG, Ray PN. Differentiation of Duchenne and Becke muscular dystrophy phenotypes with amino- and carboxy-terminal antisera specific for dystrophin. Am $\mathfrak{f} \mathrm{Hum}$ Genet 1991;48:295-304.

28 Nicholson LVB, Johnson MA, Davison K, et al. Dystrophin or a 'related protein' in Duchenne muscular dystrophy? Acta Neurol Scand 1992;86:8-14.

29 Cottin $\mathrm{P}$, Poussard $\mathrm{S}$, Mornet $\mathrm{D}$, et al. In vitro digestion of dystrophin by calcium-dependent proteases, calpains I and II. Biochimie 1992;74:565-70.

30 England S, Nicholson LVB, Johnson MA, et al. Very mild muscular dystrophy associated with the deletion of $46 \%$ of dystrophin. Nature 1990;343:180-2.

31 Klein CJ, Coovert DD, Bulman DE, et al. Somatic reversion/supression in Duchenne muscular dystrophy (DMD): evidence supporting a frame-restoring mechanism in rare dystrophin-positive fibres. Am $\mathcal{F}$ Hum Genet 1992;50:950-9.

32 Bonilla E, Schmidt B, Samitt CE, et al. Normal and dystrophin-deficient fibres in carriers of the gene for Duchenne muscular dystrophy. $\mathrm{Am} f$ Pathol 1988;133:4405.

33 Arahata K, Ishihara T, Kamakura K, et al. Mosaic expression of dystrophin in symptomatic carriers of Duchenne's muscular dystrophy. $N$ Engl f Med 1989;320:138-42.

34 Clerk A, Rodillo E, Heckmatt J, et al. Characterisation of dystrophin in carriers of Duchenne muscular dystrophy. dystrophin in carriers of Duchent
f Neurol Sci 1991;102:197-205.

35 Vainzof M, Pavanello RCM, Pavanello I, et al. Dystrophin immunofluorescence pattern in manifesting and asymptomatic carriers of Duchenne's and Becker muscular dys-

36 Glass IA, Nicholson LVB, Watkiss E, et al. Investigation of a female manifesting Becker muscular dystrophy. $\mathcal{F ~ M e d ~}$ Genet 1992;29:578-82.

37 Morandi L, Mora M, Gussoni E, Tedeschi S, Cornelio F Dystrophin analysis in Duchenne and Becker muscular dystrophy carriers: correlation with intracellular calcium and albumin. Ann Neurol 1990;28:674-9.

38 Voit T, Neuen-Jacob E, Mahler V, Jauch A, Cremer M. Somatic mosaicism for a deletion of the dystrophin gene in a carrier of Becker muscular dystrophy. Eur $\mathcal{F}$ Pediatr 1992;151:112-16.
39 Chevron MP, Tuffery S, Echenne B, Demaille J, Claustres $M$. Becker muscular dystrophy: demonstration of the carrier status of a female by immunoblotting and immunostaining. Neuromusc Dis 1992;2:47-50.

40 Hoffman EP, Garcia CA, Chamberlain JS, et al. Is the carboxyl-terminus of dystrophin required for membrane association? A novel, severe case of Duchenne muscular dystrophy. Ann Neurol 1991;30:605-10.

41 Fanin M, Danieli GA, Vitiello L, Senter L, Angelini C. Prevalence of dystrophin-positive fibers in 85 Duchenne muscular dystrophy patients. Neuromusc Dis 1992;2:41-5.

42 Wenger SL, Steele MW, Hoffman EP, Barmada MA Wessel HB. $X$ inactivation and dystrophin studies in $\mathrm{t}(\mathrm{X} ; 12)$ female. Am $\mathrm{f}$ Med Genet 1992;43:1012-15.

43 Vainzof M, Nicholson LVB, Bulman DE, et al. Sarcolemmal distribution of abnormal dystrophin in Xp21 carriers. Neuromusc Dis (in press)

44 Nicholson LVB, Bushby KMD, Johnson MA, GardnerMedwin D, Ginjaar HB. Dystrophin expression in Duchenne patients with 'in frame' gene deletions. Neuropediatrics 1993;24:93-7.

45 Vainzof M, Takata RI, Passos-Bueno MR, Pavanello RCM Zatz $M$. Is the maintenance of the C-terminus domain of dystrophin enough to ensure a milder Becker muscular dystrophy phenotype? Hum Med Genet (in press)

46 Bittner RE, Shorny S, Fer'ings R, et al. Large 'in frame' deletions in DMD resulting in sarcolemmal expression of dystrophin C-terminus but reduced expression of 6qdystrophin C-terminus but reduced expression of
dystrophin-related protein. Neuromusc Dis (in press).

47 Arikawa E, Ishihara T, Nonaka I, Sugita $H$, Arahata $K$ Immunocytochemical analysis of dystrophin in congenital muscular dystrophy. I Neurol Sci 1991;105:79-87.

48 Sewry CA, Clerk A, Heckmatt J, et al. Dystrophin abnormalities in polymyositis and dermatomysitis. Neuromusc Dis 1991;1:333-9.

49 Beggs AH, Neumann PE, Arahata $\mathrm{K}$, et al. Possible influences on the expression of $\mathrm{X}$ chromosome-linked dystrophin abnormalities by heterozygosity for autosomal dystrophin abnormalities by heterozygosity for autosomal recessive Fukuyama congenital musc

50 Gospe SM, Lazaro RP, Lava NS, et al. Familial X-linked myalgia and cramps: a non-progressive myopathy associated with a deletion in the dystrophin gene. Neurology 1989;39:1277-80.

51 de Visser M, Bakker E, Defesche JC, Bolhuis PA, van Ommen GJB. An unusual variant of Becker muscular dystrophy. Ann Neurol 1990;27:578-81.

52 McDonald TD, Medori R, Younger DS, et al. Becker muscular dystrophy or spinal muscular atrophy? Dystrophin studies resolve conflicting results of electromyography and muscle biopsy. Neuromusc Dis 1991;1:195-200.

53 Gold R, Kress W, Meurers B, et al. Becker muscular dystrophy: detection of unusual disease courses by combined approach to dystrophin analysis. Muscle Nerve 1992;15:214-18.

54 Darras BT. Molecular genetics of Duchenne and Becker muscular dystrophy. $\mathcal{F}$ Pediatr 1990;117:1-15. 